\title{
Changing Early Childhood Education Environments with Partnership, Quality Improvement, and Intensive Consultation: A Look at One Case
}

Kimberly A. Gordon Biddle, California State University, Sacramento

JaNay Brown, California State University, Sacramento
To ensure that families get the childcare services they need, Sacramento County created the Quality Child Care Collaborative (QCCC). The QCCC is a partnership of several agencies focused on improving the quality of child care provided to children and their families. The QCCC practices can be worked into other childcare programs; other counties and states can benefit from emulating the QCCC's actions, collaboration, and aims.

\section{The Quality Child Care Collaborative}

Research has long suggested the importance of offering high quality care to children and their families (Burchinal, Peisner-Feinberg, Bryant \& Clifford, 2000; Gormely, Gayner, Phillips \& Dawson, 2005; Mashburn, Pianta, Hamre, Downer, Barbarin, Bryant, Burchinal, Early \& Howes, 2008; Morrison, 2004; Newman \& Newman, 2006). Providing young children the opportunity to establish and strengthen their early physical, cognitive, psychosocial, emotional, and language skills within a warm and stimulating environment is beneficial to children and paramount for later success. Thus, to ensure that families get the childcare services they need within the Sacramento County, the Quality Child Care Collaborative or QCCC was created.

The QCCC of Sacramento County is a partnership of several agencies all focused on improving the quality of the child care being provided to children and their families. Specifically, the main goal of the QCCC is to establish and maintain quality educational environments for children and families that receive child care in centers, family child care homes, and with exempt providers. Exempt providers are family members, friends, and neighbors who often have little to no training in how to provide quality care, but who are utilized by many families to provide child care. This partnership, funded by First Five Sacramento since 2004, began with four partners including Child Action Inc., the Sacramento County Office of Education, the Sacramento County Office of Mental Health, and WestEd. The QCCC has since flourished into a collaborative now including eleven partners that each add their own unique contribution and perspective to the collective effort by filling niches specific to the specialty of that partner. The focus of this article is to explain what the Quality Child Care Collaborative does and to show how their efforts have transformed educational environments of the child care settings into high quality settings and glean policy recommendations from their experiences. Please note that early childhood provider and early childhood teacher are used interchangeably throughout this article.

\section{The Beginning}

\section{The Past, Present, and Future}

In 2004, four agencies received initial funding from First Five Sacramento to create a comprehensive infrastructure to provide services to the Sacramento County Child Care community. First, Child Action, Inc., the lead agency in the collaborative, is the resource and referral agency for the Sacramento County. Their main duty is to manage the entire collaborative, evaluate the educational environments, and write quality improvement plans. Second, the Sacramento County Office of Education, known for their inclusive education efforts, contributed to the QCCC by offering services which focused on children with special needs. Next, the Sacramento County Office of Mental Health emphasized an interest in mental health and social/emotional development of the children in child care. This perspective allowed for mental health professionals to inform the collaborative of proper mental health practices to best serve the caregivers, the children, and their families. Finally, West Ed served as the research and service agency. WestEd's contribution to the 
collaborative was a relationship-based model for promoting quality infant/toddler care. These first four agencies of the QCCC worked hard to give the collaboration its initial momentum.

With each partner in place, the QCCC created the "wheel of services", a diagram depicting each of the partners within the collaboration (Figure 1). This "wheel of services" focused on intensive consultation to child care providers concerning mental health and inclusion, and was used as a springboard for improving child care environments. Child Action, Inc. worked as the main agency facilitating and supporting the QCCC and county parents, while the two county offices formed the consultation team, and WestEd offered intensive training to care givers. All of the services provided were either established as best practices or as emerging best practices, therefore ensuring that high quality was obtained.

\section{The Next Three Years}

After two successful years, the QCCC received funding from First Five for another three years with additional partners. With a funding stipulation to expand services, the QCCC added more partners and additional services all with the intention of helping families in Sacramento County find quality educational environments in the child care setting. A special consideration was also given to families who do not speak English as a primary language, who have a child with a disability, and who have a child with a chronic physical and / or mental health condition.

The partners of the QCCC expanded to include the Los Rios Community College District, UC Davis Center for Human Services, Warm Line Family Resource Center, the County Office of Public Health, Sacramento State University, and the Child Abuse Prevention Council. Most of the partners provided trainings for the child care providers, however, each of the partners found areas that could improve the QCCC and the services offered. For example, Sacramento State assisted Child Action, Inc. with environmental assessments and giving practical experiences to service-learning students in child care centers throughout the county; the Los Rios Community College District offered a mentorship conference to the child care providers; and the consultation team also expanded to include a representative parent from the Warmline Family Resource Center.

\section{Current Program}

In addition to the aforementioned partners, today the QCCC has added Sacramento Enriches as a partner. Sacramento Enriches is a non-profit organization that utilizes best practices to build community. This organization assists the QCCC by creating a wider distribution network of parent outreach. Additionally, given the mandate by First Five to expand services, the QCCC has found other ways to keep growing. They reach out to families and providers who serve a number of children for whom English is not their first language, including those who speak Spanish, Russian, Chinese, and Hmong. They also provide outreach to providers who want to obtain their BA degree and aid family, friends, and neighbors who are exempt providers. As the QCCC continues to grow and expand, it is committed to offering focused, coherent, comprehensive, and integrated support services for child care providers and the families they serve.

\section{The Future}

The QCCC is in the throes of applying for another five years of funding from First Five. No additional partners are being added, but services are still being expanded. For instance, Sacramento County Office of Education has added school readiness to its QCCC goals. The wheel of services is being transformed to a pyramid (Figure 2) of services in order to reflect the tiered nature of the services and the focus on another best practices model for social and emotional development. This model of best practices comes from the Center on Social and Emotional Foundations for Early Learning (CSEFEL). CSEFEL is being adapted by the State of California and other states across the country as a best practice model for training providers and parents to enhance early social and emotional development and behavior. The base of the pyramid represents environmental interventions that are good for all children. The next two levels of the pyramid increase in intensity by focusing on children who need supplemental services. The highest level of the pyramid represents acute services offered to children who are most in need.

\section{QCCC Structure and Activities}

Overall, the QCCC utilizes an eclectic array of best practice models to provide services to child care providers/ teachers and parents. At the current time, the partners are: Child Action, Inc., Sacramento County Office of Education, Sacramento County Mental Health, WestEd, Sacramento County Public Health, Sacramento State University, Los Rios Community College District, UC Davis Center for Human Services, Warmline Family Resource Center, Child Abuse Prevention Council, and Sacramento Enriches. Child Action, Inc. still acts as the lead agency in assuring that all of the services are provided in a professional manner. As mentioned previously, the image of the "wheel of services" was used at first, but now a service pyramid is utilized to represent the tiered nature of the services. With the wheel, all of the partners and their services are contained on a segment of the wheel. On the pyramid, the services are represented by the nature of their intensity with general environment enhancing services as a foundation and intensive, consultative services at the top of the pyramid.

\section{Services Provided}

One of the central services provided by the QCCC is an incentive program for child care providers to obtain education 
and meet licensing requirements related to obtaining a child development permit and beyond. For example, the Sacramento Comprehensive Approaches to Raising Educational Standards Program (CARES) Program and the QCCC offer workshops and seminars that teachers can attend to gain professional development credits. Furthermore, CARES offers monetary stipends for those involved in their program. This CARES program is geared for keeping teachers learning and rewarding them as they go.

Another major service is aiding child care providers as they develop and implement quality improvement plans by means of an initial environmental screening and a subsequent plan by a child development specialist. Additionally, the QCCC provides an interdisciplinary consultation team that provides on-going and intensive consultation to the providers with children that have special needs. These services help teachers to include children with special needs into their regular, everyday programs. Other services include helping families understand what quality child care is and helping them to obtain that care, presenting a number of trainings to parents and child care providers concerning issues such as observing and assessing young children, preventing child abuse, preventing the flu and other illnesses, and awareness of basic developmental milestones. Some of the trainings and other services are offered in languages other than English.

As mentioned before, the QCCC is a collaborative, the services are delivered in an organized and coordinated fashion with Child Action, Inc. managing all of them. The goal of all of these services is improving the quality of care and education that the children receive. These services help transform early childhood education classrooms through the development and implementation of quality improvement plans and the intensive consultation given by the consultation team. The quality improvement plans are based on assessments of the educational environment with the Harms and Clifford environmental rating scales. These assessment scales look at certain aspects of the environment including safety, health, and appropriate development. After these assessments are conducted, a member of the QCCC team at Child meets with the child care providers and together they create a quality improvement plan. Completing the steps of the improvement plan gives caregivers a chance to renovate and ameliorate the educational environment that they provide.

Not only do rating the classroom then devising and implementing a plan improve the educational environment, but the consultation team helps in other domains that aid the social, emotional, and behavioral development of children, especially those with special needs. The consultation team also helps to transform the educational environmental quality. Competency within the three previously mentioned developmental domains are closely related to cognitive competency in children from birth to five years old (Driessen, 2003) and impacts their educational trajectory for years to come. When QCCC has a child that they want to help, the team goes in to the childcare setting and observes how all of the children and teachers interact with a particular emphasis on observing that focal child. Subsequently, suggestions are made about how to transform the environment so that the focal child has more positive interactions with the other children and teachers, and ultimately establishes a better learning environment for all children in care. These suggestions are implemented and then the consultation team member returns to observe. More intensive changes are made if needed and occasionally, the consultation team member models interactions with the focal child and gives direct coaching or mentoring to the teachers on how to interact with the focal child.

\section{Recipients of Services}

The QCCC provides services to early childhood teachers of children aged birth to five years of age in Sacramento County. They offer services to child care centers, family child care homes, exempt providers, and parents. Exempt providers are family members, friends, and neighbors of the children in care who do not have a license to give care. A number of children are in these sorts of arrangements and the quality of the care they receive varies a great deal. Therefore, aid from the QCCC helps these venues that provide care for children to provide the best care possible no matter if the child is in a center or a home. Parents also receive services through the QCCC. Not only can parents receive assistance in Action, Inc. finding care for their children, parents are also shown how to identify quality care. Furthermore, parents receive additional assistance and support if their child has a special need.

\section{Impact of the QCCC on the Educational Environments of the Service Recipients}

It is evident that the QCCC believes in working with others to better the services offered to the educators, families, and children in the Sacramento County; their efforts certainly make a positive impact on the community In the first five years, the QCCC provided care to a number of centers, family child care homes, and parents. During the current period, additional centers, homes, exempt providers, and parents have received services. Furthermore, providing opportunities for teachers to advance their education, ultimately leading to higher quality care, is another way that the QCCC works in collaboration with other programs, such as the CARES, to improve educational environments. Offering classes and professional development as well as stipends to pursue higher degrees, helps educators to move up the Professional Matrix, a grid which specifies the amount of education, working hours, and ECE units necessary to advance in the field of ECE. The education and hours necessary for advancements through this Professional Matrix ultimately provides teachers with the necessary tools for classroom improvement.

Based on evaluation reports, the collaboration between the QCCC and other programs have led to several noticeable 
increases in different areas within the early childhood education field. Specifically, in the 2008/2009 year, 343 participants applied for CARES stipends with 115 of those participants becoming qualified for moving to the next level of the Professional Matrix. Also, the amount of high quality accredited spaces that can serve children increased by $46 \%$. Additionally, of the participating family, friends, and neighbor providers taking part in the CARES program, $57.1 \%$ of these participants received a child care license and $42.9 \%$ moved closer toward receiving a child care license.

In addition to offering services to educators, the QCCC utilizes three environment rating systems to assess the educational environment of the classrooms: the Early Childhood Environment Rating Scale, Revised Edition (ECERS-R) used to assess children aged 2.5 to 5 years old; the Infant/Toddler Environment Rating Scale, Revised edition (ITERS-R) used to assess children birth to 2.5 years old; and the Family Child Care Environment Rating Scale, Revised Edition (FCCERS-R) used to asses children from birth through school age who attend in home child care programs. Scores on these scales range from 0 , indicating poor care, to 7 , meaning enhanced development and care is taking place. Each of the environmental scales use different subscales to rate the environment including Space and Furnishings, Personal Care Routines, Language or Listening and Talking, Activities, Interactions, Program Structure, and Parents, Providers, or Staff. After the child care centers are assessed, program managers are able to pinpoint where their programs are strongest and weakest, and begin implementing changes to better the services they provide. Furthermore, even if it takes time to make large improvements in the classroom based on these ratings, using these scales increase the overall awareness of what it takes to make a quality classroom. These ratings scales are great indicators of what educators need to do to improve their classrooms, and they serve a major role of comparing where a classroom rates before improvements are made and to how they rate once evaluated again later.

As the QCCC continues to work tirelessly to improve educational environments, their efforts have definitely made a difference. Both qualitative and quantitative data have shown an impact. Based on quantitative data which compared the 2007/2008 ECERS scores to the 2008/2009 scores, the data shows that on average 6 scores increased, 6 scores decreased, and 5 scores stayed the same or had no more than a .5 change. Additionally, considering the overall average scores during the 2008/2009 fiscal year, major gains were shown upon comparing the initial environmental rating assessment taken earlier in the year, and the later assessment. Specifically, 46 centers showed gains in their average ratings from 4.3 at the earlier assessment, to 5.3 during the later assessment. Furthermore, the 56 family child care centers showed an average gain of 4.1 at the initial assessment, to 5.2 during the later assessment. This data shows that the QCCC and its collaborators have aided in score increases and maintenance of quality. Despite these gains, the QCCC still strives for perfection, and is constantly adding more services and updating the best practices used to ensure that everyone's needs are met as these programs work toward improvement, and as the collaboration offers the best services it can.

Just as the quantitative data showed positive gains after working with the QCCC and its collaborators, the qualitative data shows that many caregivers value and think highly of the services provided, based on the feedback they offered. One child care provider explained that:

"I received one-on-one counseling on what and how to handle the issues I had with my childcare such as information and tips on speech and language development and how to encourage more speaking. The OT helped me so much with supplies, training and support. I have been helped on ways to talk with parents about different disabilities."

In this case, the QCCC seemed to have helped boost this provider's confidence in helping parents while giving her both tangible and intangible means to improve the care she offers. Additionally, providers were quoted saying "I wish I had found out about these services years ago!" and "I value the care and compassion everyone has shown. Nothing feels any better than to have someone listen to your problems or concerns and then work with you to fix the problem."

Another provider explained her feelings about the QCCC saying:

"Our field of ECE in general and we in particular feel very fortunate to have you as part of our support members. The ideal educational system should consist on this camaraderie and support as we feel from you to our students. Thank you!"

Thus, not only did she feel that her center was improved by the QCCC, but the Early Childhood Education field as a whole is bettered by the efforts made by the collaborative. These quotes are evidence that services provided by the QCCC were valuable to those receiving it. Giving providers the support they need not only benefits the provider, but trickles down adding quality to the center and improving the quality of the educational environments and the services children and families receive.

\section{Policy Recommendations}

The QCCC has been in existence now for seven and half years and has had some relative success as shown in the previous section. It has also been recognized as a model collaborative by the National Association for the Education of Young Children in its Young Children journal (Friedman, 2006). Therefore, there have been lessons learned and practices utilized that may be helpful for others as they engage in transforming environments for young learners.

One suggestion that can be utilized everywhere by organizations geared at improving educational environments 
is to have an interdisciplinary intervention team. This team can consist of educators at various levels (early childhood, pre-service, and post degree), mental health professionals, educators that focus on children with special needs, parents, physical health professionals, child development specialists, and community representatives. It is important for all of these players to be at the table and to communicate with each other on a regular basis. Team members should be aware of the services and expertise that each member brings to the collaborative and be willing to hear everyone's perspectives, especially since all team members should have a common goal: better quality for our children. With this in mind, referrals to other team members as the need arrives should be common.

In order for a team and the child care providers to transform the educational environment of the children, time is needed for collaboration, conversation, and discussion. Regular meetings and more informal contact should occur quite frequently allowing for timely and consistent communication; the providers should have time scheduled daily, even if only for 15 or 20 minutes, to ruminate over and discuss how to improve the classroom. Each member of the team and the provider should be respected and expected to share their perspective and expertise.

Another suggestion is to support providers/teachers of the young children as they continue their formal education to a MA degree or even beyond. Education is integral in improving the teachers' skills, knowledge, and abilities and education works as catalysts for a positive change in the classroom. The employers of the early childhood teachers should assist with this process by providing flexible schedules, space for studying and learning, and monetary aid. Local governmental agencies and nonprofits or foundations should also provide support for the providers to continue their formal education. Furthermore, education allows for perspectives and professionalism to become more refined. This will also help others to see how important it is to educate young children and garner more respect for the field.

Beyond formal education, another suggestion for providers/teachers of young children is to continue their professional development by attending workshops and conferences as well as reading materials that contain current research and practices in the field. Employers and local government agencies should support and provide these efforts. At least four trainings, workshops, or conferences should be attended each year, and these trainings can cover an array of topics varying from marketing child care and best business practices to communicating with parents and building pre-literacy skills. Early childhood education teachers should also be exposed to advocacy methods in addition to the rudimentary duties such as educating children and ensuring that they are healthy, safe, cognitively stimulated, and happy.

Parents play such an important role in making sure their child receives quality education. They can also play a key role in transforming the educational environment of their children if that becomes necessary. Parents are not always aware of what a quality education is, nor are they always aware of the power that they have. Thus, another suggestion would be to inform parents about advocacy methods, the characteristics of quality early education, and avenues for communicating with the educators of their children. The interdisciplinary team of experts that work with providers should also work with parents and assist parents and providers in working together. It is imperative for the collaborative team of experts to communicate with, educate, and outreach to parents. Accordingly, experts, teachers, and parents in a young child's life should work together to transform the environment.

Funding is always a consideration when creating a collaborative interdisciplinary team. The QCCC is mainly funded by First Five Sacramento, a county-based agency funded by a state-level foundation, First Five California. However, each partner in the collaborative contributes a certain portion of their own funds to the effort. Additionally, with each new funding cycle, new services have to be offered to the providers. These types of funding mechanisms are recommended as a matter of policy to any organization or entity trying to establish an educational collaborative. The funding should be considerable and permanent or as permanent as possible, much like the funding for the Quality Child Care Collaborative. Ideally, governmental agencies and commercial businesses should also contribute to the funding through direct funds or in-kind gifts. Having such entities consider children and child care in everyday decisions and funding decisions is a welcome occurrence. The funding of such a collaborative should be considered long-term and incorporated into the every day fabric of the district, neighborhood, county, or geographic area.

Funding is incredibly important; so is the means of evaluating whether a program is performing as effectively as it should. How will the funders know that the collaborative is a success and is meeting its goals without tools of assessment? The Harms \& Clifford standardized instruments are the hallmark in the field and they are generally available and appropriate. Some states may also have standardized instruments that measure educational environmental quality or child development milestones. For instance, California has the Desired Results Developmental Profile - Revised (DRDP-R, The DRDP-R measures children's developmental milestones in the area of cognition, social and emotional development, language, gross and fine motor, and self-help skills. Additionally, formative assessment and evaluation can occur with each workshop through mixed method surveys. These surveys contain closed and open-ended questions.

Also, teachers can measure children's learning with natural and structured observation. Parents' knowledge, satisfaction, beliefs and perceptions can also be measured through mixed methods surveys and focus groups. Although surveying 
parents is informative, the most important outcomes are the children's knowledge, skills, behaviors, and milestones. These should be assessed rigorously and thoroughly with standardized and non-standardized methods. In addition to the aforementioned methods of assessment, portfolios of the student's work can be gathered, pictures and videos can be taken (with requisite permission). All of these methods can be used to document the success of the endeavor, as documenting success is quite important.

The efforts of the QCCC to change educational environments do not go unnoticed. In the words of a provider the "QCCC made me feel professional and very important." As the QCCC continues to work and expand, its practices can be worked into other childcare programs, and the creation of a collaborative can be adopted by other counties and states hoping to improve the child care services offered to their communities. As QCCC aims to continuously improve, it will steadily move toward the ultimate goal: creating quality educational environments for all children in care in Sacramento County. All counties and states can benefit from emulating the QCCC's actions, collaboration, and aims.

\section{REFERENCES}

Burchinal, M. R., Peisner-Feinbgerg, E., Bryant D., \& Clifford, R. (2000). Children's social and cognitive development and child-care quality: Testing for differential associations related to poverty, gender, or ethnicity. Applied Developmental Science, 4(3) 149-165.doi: 10.1207/S1532480XADS0403.

Driessen, G. (2003). Family and child characteristics, childrearing factors, and cognitive competence of young children. Early Child Development and Care, 173(2-3), 323-339. doi:10.1080/03004430303102.

Friedman, S. (2006). Coming together for children: Six community partnerships make a big difference. Young Children.36-31.

Gormley, W., Gayer, T., Phillips, D., \& Dawson, B. (2005). The Effects of Universal Pre-K on Cognitive Development. Developmental Psychology, 41(6), 872-884. doi:10.1037/00121649.41.6.872.

Mashburn, A., Pianta, R., Hamre, B., Downer, J., Barbarin, O., Bryant, D., Burchinal, M., Early, D. M., Howes, C. (2008). Measures of classroom quality in prekindergarten and children's development of academic, language, and social skills. Child Development, 79(3), 732-749. doi:10.1111/j.14678624.2008.01154.x.

Morrison, G.S. (2004). Early Childhood Education Today (9th ed.). New Jersey: Merrill Prentice Hall. Newman, B.M, Newman,
P.R. (2006). Development Through Life: A Psychosocial Approach. California: Thomson Wadsworth. 
Appendix A

Quality Child Care

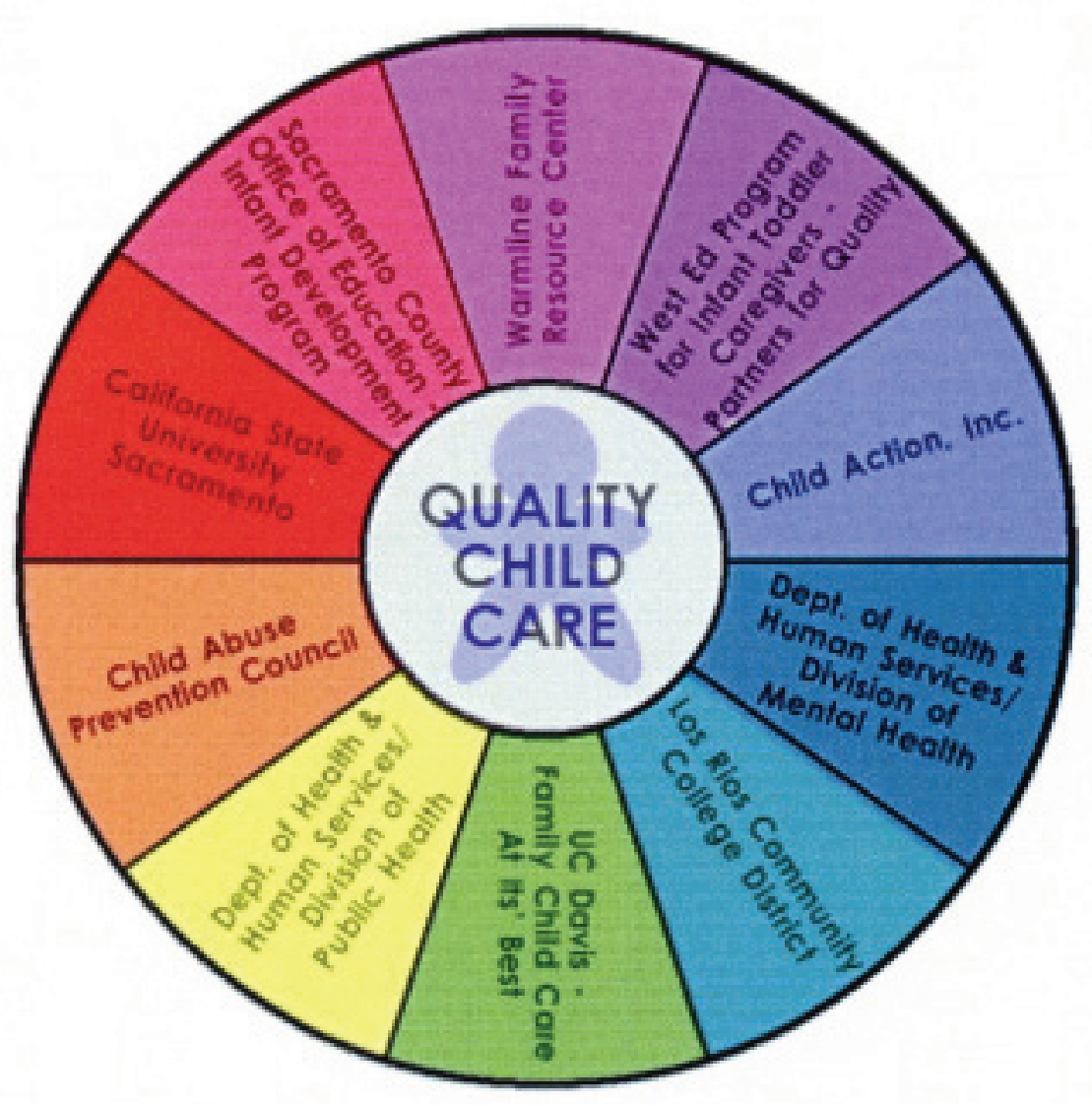

Source: Child Action, Inc. 
Appendix B

Effective Care Practice

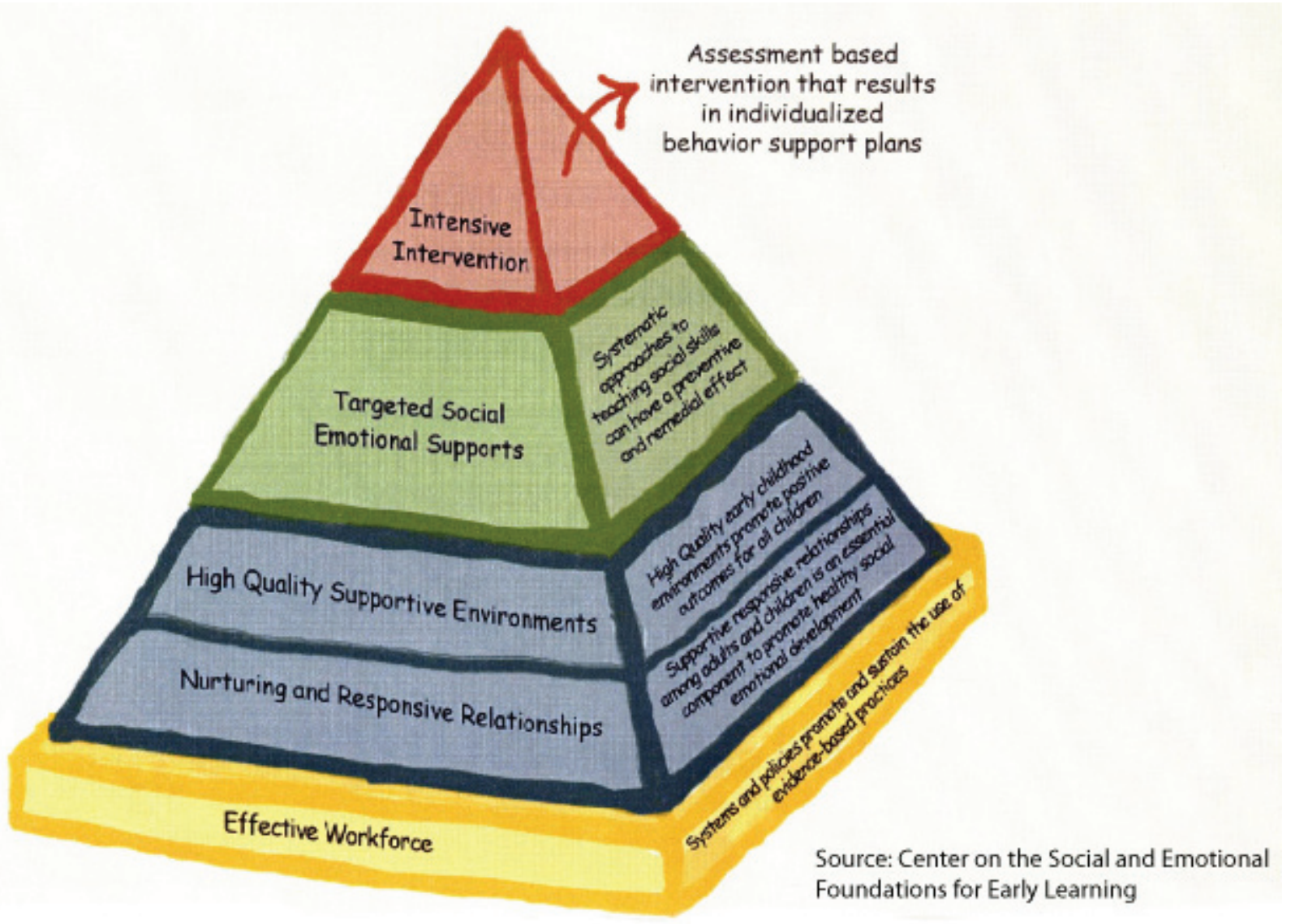

